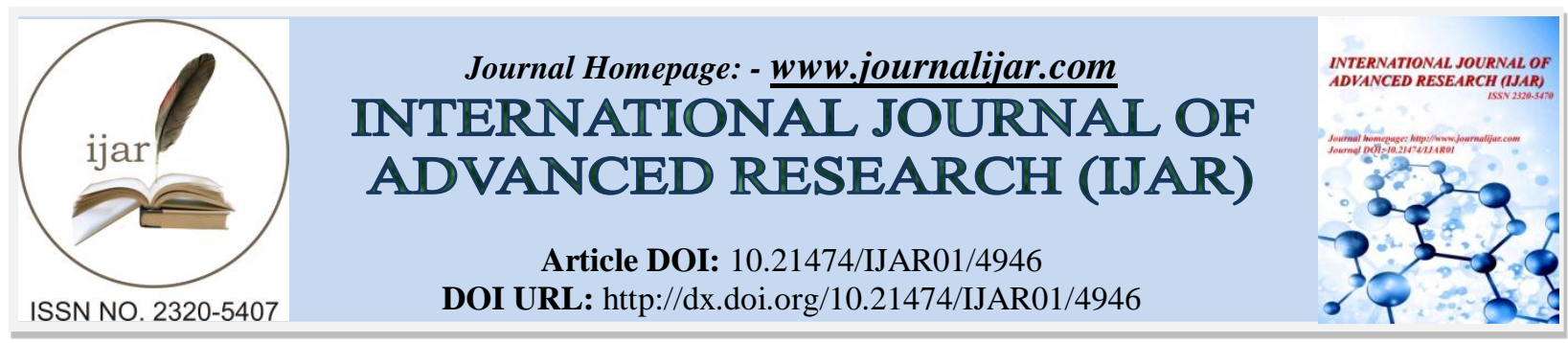

RESEARCH ARTICLE

\title{
ANTI-ULCER ACTIVITY OF TERMINALIA LAXIFLORA ENGL. AND DIELS LEAVES EXTRACTS AGAINST ASPIRIN INDUCED GASTRIC ULCER IN RATS.
}

\author{
Medhat M. Menshawy ${ }^{1}$, Mohamed A. El Raey ${ }^{2}$, Abdel Hamid A. Hamdy ${ }^{3}$ and Abdel Razik H. Farrag ${ }^{4}$. \\ 1. Department of Biology, Center of Basic Sciences, Misr University for Science and Technology, $6^{\text {th }}$ October \\ City. \\ 2. Departments of Phytochemistry \& Plant Systematic. \\ 3. Chemistry of Natural \& Microbial Products. \\ 4. Pathology, National Research Centre, Dokki, Cairo, Egypt.
}

\section{Manuscript Info}

Manuscript History

Received: 24 May 2017

Final Accepted: 26 June 2017

Published: July 2017

Key words:-

Antiulcer ulcer, Terminalia, aspirin, rats, plant phenolics.

\section{Abstract}

Background/Aim: Gastric ulcer is one of the most widespread gastrointestinal disorders resulting from weakness of a gastric mucosal defense. Several drugs are available to address ulcer; however, these drugs are associated with several side effects. Previous studies have confirmed the efficacy of herbal plants extracts for possible treatment of this disease. This research aims to evaluate the antiulcer properties of Terminalia laxiflora extracts. Methods: Water and its fractions, total methanol, dichloromethane, ethyl acetate, butanol extracts from the leaves of Terminalia laxiflora were evaluated for their antiulcer activity using aspirin as ulcerogen in rats. All administration was given one hour prior to aspirin. Macroscopic, hisopathological and histochemical examinations were performed the effect of these extracts on ulcer. Results: All extracts showed significant inhibitory activity. The percentages of inhibition for the different extracts equal to $54.21,64.86,61.71,76.84,75.92,79.47$, and $86.05 \%$ for water 1 , water 2, methanol, DCM, ethyl acetate, and butanol as compared to non-pretreated aspirin group. Butanol extract was found to possess remarkable ulcer-protective properties at $50 \mathrm{mg} / \mathrm{kg}$ when compare to other the other extracts. The effect of ulcer protection $86.05 \%$ was produced and standard drug, Ranitidine, gave $81.57 \%$ of ulcer protection, respectively. Conclusion: We conclude that Terminalia laxiflora extracts are potential sources of new antiulcer agents.

Copy Right, IJAR, 2017,. All rights reserved.

\section{Introduction:-}

Peptic ulcer disease is disorder used to describe a heterogeneous group of condition with ulcerations. It is characterized by the disruption of the normal mucosal integrity of the esophagus, stomach, or duodenum (Kumar, et al, 2011). Gastric ulcer is one of the most common disorders (Alkofahi, and Atta 1999). The continuously exposed to agents such as pepsin, acid, bacterial products, bile acids, and steroidal and non-steroidal anti-inflammatory drugs (NSAIDS) increases the gastric ulcer prevalence (Mota, et al, 2009). These agents have been implicated in the pathogenesis of gastric ulcer, including enhanced gastric acid and pepsin secretion, inhibition of prostaglandin synthesis and cell proliferation growth, diminished gastric blood flow and gastric motility (Toma, et al, 2005). 
Ulcers are primarily caused by an imbalance between some endogenous aggressive and protective factors in the stomach such as acid-pepsin secretion, integrity of the mucosal barrier, mucus secretion, blood flow, cellular regeneration, prostaglandins, and growth factors (Yuan, et al., 2006; Freitas, et al. 2008). Medications are used to relieve the pain, heal ulcerations and delay recurrence of ulcerations. These include antibiotics antacids and proton pump inhibitors (Tepperman and Jacobson, 1994). Several drugs are available in the market for gastric ulcer therapy; however, most of these drugs are associated with unwanted side effects (Shirode, 2008).

Aspirin is a potent non-steroidal anti-inflammatory drug (NSAID) that is used for the treatment of rheumatoid arthritis and related diseases as well as the prevention of cardiovascular thrombotic diseases. Gastric ulcer associated with the use of aspirin is a major problem. Many factors such as gastric acid and pepsin secretion, gastric microcirculation, prostaglandin E2 (PGE2) content (Laine, et al. 2008) and proinflammatorycytokines interleukin (IL-1 $\beta$ ) and tumor necrosis factor (TNF)- $\alpha$ play important role in the genesis of gastric mucosal damage, and its subsequent development (Wang, et al. 2008; Wallace 2008).

Plant extracts are some of the most attractive sources of new drugs, and have been shown to produce promising results for the treatment of gastric ulcer (Pillai et al, Among these extracts are the extracts rich in phenolics (De Barros et al., 2008, Sumbul et al., 2011, Dubey et al., 2013).

The genus Terminalia was reported to be rich in phenolics compounds (Mohiuddin et al., 2015). Terminalia laxiflora was reported to have antimicrobial and antiviral activities (Muddathir et al. 2013, Rashed and Ono 2013). It was also reported that it contain mixture of phenolic compounds such as quercetin, rutin, vitexin, isovitxin, ellagic acid derivatives, gallic acid and methyl gallate. There are many reports about the potential antiulcer activity of these compounds; gallic, quercetin and rutin (Sumbul et al. 2011, Dubey et al. 2013, Sen et al. 2013).

Therefore, the objective of the present study was to investigate the gastroprotective activities of Terminalia laxiflora leaves water extract and its fractions; methanol, butanol, ethyl acetate and methylene chloride by using aspirin model and to study the effect of phenolic compounds on antiulcer activity.

\section{Materials and Methods:-}

\section{Plant materials:-}

Terminalia laxiflora leaves were collected from Zohreya Garden, Cairo, Egypt on September 2013 and authenticated by Dr. Mohamed El Gebally, Former Researcher of Botany, National Research Center, Dokki, Cairo, Egypt.

\section{Extraction:-}

One kilogram of $T$. laxiflora dried leaves was extracted by hot $\mathrm{H}_{2} \mathrm{O}$ for half hour. The resultant extract was filtered off and dried under reduced pressure, then freeze dried and re-extracted by methanol. The methanol $100 \mathrm{~g}$ extract was suspended in water and partitioned by methylene chloride $5 \mathrm{~g}$, ethyl acetate $22 \mathrm{~g}$ and butanol $27 \mathrm{~g}$, respectivel

\section{The presence of flavonoids test was performed by Shinoda test:-}

Shinoda test: To an alcoholic solution of the sample, add magnesium powder and a few drops of concentrated $\mathrm{HCl}$; orange, pink, red to purple colors will appear when flavones, flavonols, the corresponding 2, 3-dihydro derivatives, and/or xanthones are present. It is advisable to add t-butyl alcohol before adding the acid to avoid accidents from a violent reaction; the colored compounds will dis- solve into the upper phase. By using zinc instead of magnesium, only flavanonols give a deep-red to magenta color; flavanones and flavonols will give weak pink to magenta colors or no color at all (Cannell, R.J., 1998).

\section{Test of galloyl esters was performed by Potassium Iodate $\mathrm{KIO}_{3}$ :-} (saturated aqueous solution) (Haddock et al., 1982).

\section{Test of hexahydroxydiphenoyl esters;-}

Nitrous acid (Gupta et al., 1982): To a volume of $100 \mathrm{ml}$ ice cold aqueous NaNO2 solution (10 \%) few drops (5-10) of glacial acetic acid are added, the spray is used immediately after preparation.

\section{Total phenol:-}

The total phenolic content was determined according to the Folin-Ciocalteu procedure (Zilic et al., 2012). 


\section{Total flavonoids:-}

The total flavonoid content was determined according to (Zilic et al., 2012) using aluminum chloride (AlCl3) colorimetric assay.

\section{Biological study:-}

Drugs:-

Aspirin was obtained from Chemical Industries Development (CID) Giza (Egypt) as tablets each tablets contain 75 $\mathrm{mg}$ acetyl salycilic acid, and was suspended in $0.5 \%$ carboxymethyl cellulose in water (El Nasr Chemicals Company, Egypt). Ranitidine was kindly provided by Glaxo Smith Kline, Egypt. The drugs were prepared immediately before use.

\section{Animals:-}

Female albino rats, six weeks of age and weighing 130-160 grams were purchased from the Animal House Lab, National Research Centre, Cairo, Egypt. The animals were housed in a temperature room $\left(24 \pm 2{ }^{\circ} \mathrm{C}\right)$ with relative humidity of $55 \pm 10 \%$ and $12 \mathrm{~h}$ light/dark cycle (lights on at 7:00 a.m.). The animals had free access to tap water and diet. All the animals received care according to the guidelines set out by the Institutional Animal Use and Care Committee of National Research Centre.

\section{Experimental Design:-}

Fifty four rats were fasted for 18 hours but excess water was allowed. The rats were randomly divided into 9 groups, 6 rats of each follows:

1. Control (non-ulcer non-treated) group: In which animals were left freely wandering in their cages for 3 hours.

2. Aspirin (non-pretreated) group: In which rats received no further medication other than aspirin $(200 \mathrm{mg} / \mathrm{kg}$, orally).

3. Water extract I of Terminalia and Aspirin group: In which extract $(50 \mathrm{mg} / \mathrm{kg}$, orally) was given one hour prior to aspirin administration.

4. Water extract II and Aspirin group: In which extract (100 mg/kg, orally) was given one hour prior to aspirin administration.

5. Total methanol extract and Aspirin group: In which extract $(50 \mathrm{mg} / \mathrm{kg}$, orally) was given one hour prior to aspirin administration.

6. Dichloromethane (DCM) and aspirin group: In which extract $(50 \mathrm{mg} / \mathrm{kg}$, orally) was administered one hour before aspirin administration.

7. Ethyl acetate extract and aspirin group: In which extract $(50 \mathrm{mg} / \mathrm{kg}$, orally) was administered one hour before aspirin administration.

8. Butanol extract and aspirin group: In which extract $(50 \mathrm{mg} / \mathrm{kg}$, orally) was administered one hour prior to aspirin administration.

9. Ranitidine and aspirin group: In which $(50 \mathrm{mg} / \mathrm{kg}$, orally) was administered one hour prior to aspirin administration.

\section{Macroscopic Examinations:-}

After completion of the 6 hours after aspirin administration, rats were killed by an overdose of ether. Their stomachs were removed and opened along the greater curvature for scoring gastric mucosal lesions. Gastric mucosal lesions were expressed in terms of the ulcer index (UI) (Abdallah et. al., 2011, Nassar, et. Al., 2013), which depends on the calculation of a lesion index using scoring system based on the severity of each lesion. The severity factor was defined according to the length of the lesions. Severity factor $0=$ no lesions; $1=$ petechiae; $2=$ erosions $<1 \mathrm{~mm} ; 3=$ erosions of $1-2 \mathrm{~mm} ; 4=$ erosions of $2-4 \mathrm{~mm}$ and $5=$ erosions $>4 \mathrm{~mm}$. the partial scores were then summed to obtain the ulcer index of the animal examined. The UI for each group was taken as the mean lesion score of all the rats in that group. The numbers of ulcers were counted using magnifying lenses. Each ulcer was then measured with a vernier to assess the diameter. The percent protection with each extract dose was also calculated by the following formula (Suzuki et al. 1976):

$\%$ Protection $=\left[\left(\mathrm{UI}_{\text {aspirin }}-\mathrm{UI}_{\text {treated group }}\right] / \mathrm{UI}_{\text {aspirin }}\right] \times 100$, where UI stands for ulcer index.

\section{Hisopathological and Histochemical:-}

Stomach specimens were taken immediately after scoring the gastric lesions and fixed by immersion in $10 \%$ neutral formaldehyde. Paraffin sections were prepared and stained with hematoxylin-eosin for histopathological 
examinations or with PAS to detect the mucus changes in the stomach mucosa of all groups. The sections were mounted and observed under light microscope for details.

\section{Statistical Pnalysis:-}

Results were expressed as the mean \pm S.E. Statistical significance between groups was determined by one-way analysis of variance (ANOVA) followed by Tukey-Kramer's post test (GraphPad Prism 4.03, GraphPad Software, $\mathrm{CA})$ at the selected level of significance of $\mathrm{P}<0.05$.

\section{Results:-}

\section{Macroscopic investigations:-}

Regarding to gross examination of stomach, no lesions were seen in control non-ulcer non-treated group (Fig. 1-A). In aspirin group, multiple gastric mucosal erosion in the glandular part of the stomach, most often 1-4 mm in size, or petechial bleeding at the time of observations (Fig. 1-B). Gross examination of stomach of water I, water II, methanol, DCM, ethyl acetate, butanol and ranitidine groups are presented in Fig. 1-C-I, respectively. Table 1and 2 summarizes the results obtained in aspirin-induced gastric ulceration in rats. The UI was $7.6 \pm 0.11,3.48 \pm 0.22$, $2.67 \pm 0.36,2.91 \pm 0.22,1.76 \pm 0.32,1.83 \pm 0.50,1.56 \pm 0.12,1.06 \pm 0.92$, and $1.34 \pm 0.42$ for aspirin group, water extract I and aspirin, water extract II and aspirin, methanolic extract and aspirin, dichloromethane extract and aspirin, ethyl acetate extract and aspirin, butanol extract and aspirin, and ranitidine and aspirin, respectively. The results showed significant reduction in the severity of ulcer and ulcer index of the treated groups as compared with aspirin group. The percentages of protection of the different extracts equal to 54.21, 64.86, 61.71, 76.84, 75.92, $79.47,86.05$ and $81.53 \%$ for water I, water II, methanol, DCM, ethyl acetate, butanol and ranitidine, respectively, as compared to aspirin group.

Butanol extract was found to possess remarkable ulcer-protective properties at $50 \mathrm{mg} / \mathrm{kg}$ when compared to the other extracts. The effect of ulcer protection $86.05 \%$ was produced and standard drug, Ranitidine, gave $81.57 \%$ of ulcer protection, respectively.

\section{Histopathological Results:-}

Stomach showed no histopathological changes in control group. Normal histological of gastric mucosa was seen (Fig. 2-A). While, stomach of aspirin group showed focal necrosis of gastric mucosa associated with mucosal and submucosal eosinophilic cells infiltration. Stomachs of extracts for water I, water II, methanol, DCM, ethyl acetate, butanol and ranitidine drug groups showed few histopathological changes (Fig. 2-C-I, respectively).

Table 1:- Scoring shows the severity of lesions of aspirin induced gastric ulcer in different groups of rats.

\begin{tabular}{|l|c|c|c|c|c|c|}
\hline \multirow{2}{*}{ Treatment and dose } & \multicolumn{7}{|c|}{ Histological lesions } \\
\cline { 2 - 7 } & $\begin{array}{c}\text { no } \\
\text { lesions }\end{array}$ & petechiae & $\begin{array}{c}\text { erosions } \\
(<1 \mathrm{~mm})\end{array}$ & $\begin{array}{c}\text { erosions } \\
(1-2 \mathrm{~mm})\end{array}$ & $\begin{array}{c}\text { erosions } \\
(2-4 \\
\mathrm{mm})\end{array}$ & $\begin{array}{c}\text { erosions } \\
(>4 \mathrm{~mm})\end{array}$ \\
\hline 1. Control group & 0 & 0 & 0 & 0 & 0 & 0 \\
\hline 2. Aspirin group & - & 1 & 2 & 3 & 4 & 5 \\
\hline 3. Water extract I and aspirin group & - & 1 & 2 & 3 & - & 5 \\
\hline 4. Water extract II and aspirin group & - & 1 & 2 & 3 & 4 & - \\
\hline 5. Methanol extract and aspirin group & - & 1 & 2 & 3 & - & - \\
\hline 6. DCM extract and aspirin group & - & 1 & 2 & 3 & - & - \\
\hline 7. Ethyl acetate extract and aspirin group & - & 1 & 2 & 3 & - & - \\
\hline 8. Butanol extract and aspirin group & - & 1 & 2 & - & - & - \\
\hline 9. Ranitidine and aspirin group & - & 1 & 2 & - & - & - \\
\hline
\end{tabular}

Table 2:- Effect of various extracts of Terminalia against Aspirin induced gastric ulcer in rats

\begin{tabular}{|l|c|c|}
\hline Treatment & Ulcer Index & \% of protection \\
\hline 1. Control group & - & - \\
\hline 2. Aspirin group & $7.6 \pm 0.11$ & - \\
\hline 3. Water extract I and aspirin group & $3.48 \pm 0.22$ & $54.21^{*}$ \\
\hline 4. Water extract II and aspirin group & $2.67 \pm 0.36$ & $64.86^{*}$ \\
\hline 5. Methanol extract and aspirin group & $2.91 \pm 0.22$ & $61.71^{*}$ \\
\hline
\end{tabular}




\begin{tabular}{|l|c|c|}
\hline 6. DCM extract and aspirin group & $1.76 \pm 0.32$ & $76.84^{*}$ \\
\hline 7. Ethyl acetate extract and aspirin group & $1.83 \pm 0.50$ & $75.92^{*}$ \\
\hline 8. Butanol extract and aspirin group & $1.56 \pm 0.12$ & $79.47^{*}$ \\
\hline 9. Ranitidine and aspirin group & $1.40 \pm 0.42$ & $81.57^{*}$ \\
\hline
\end{tabular}

Data expressed as mean \pm SE $(n=6)$

$* \mathrm{P}<0.05$, was consider statistically significant when compared to aspirin group
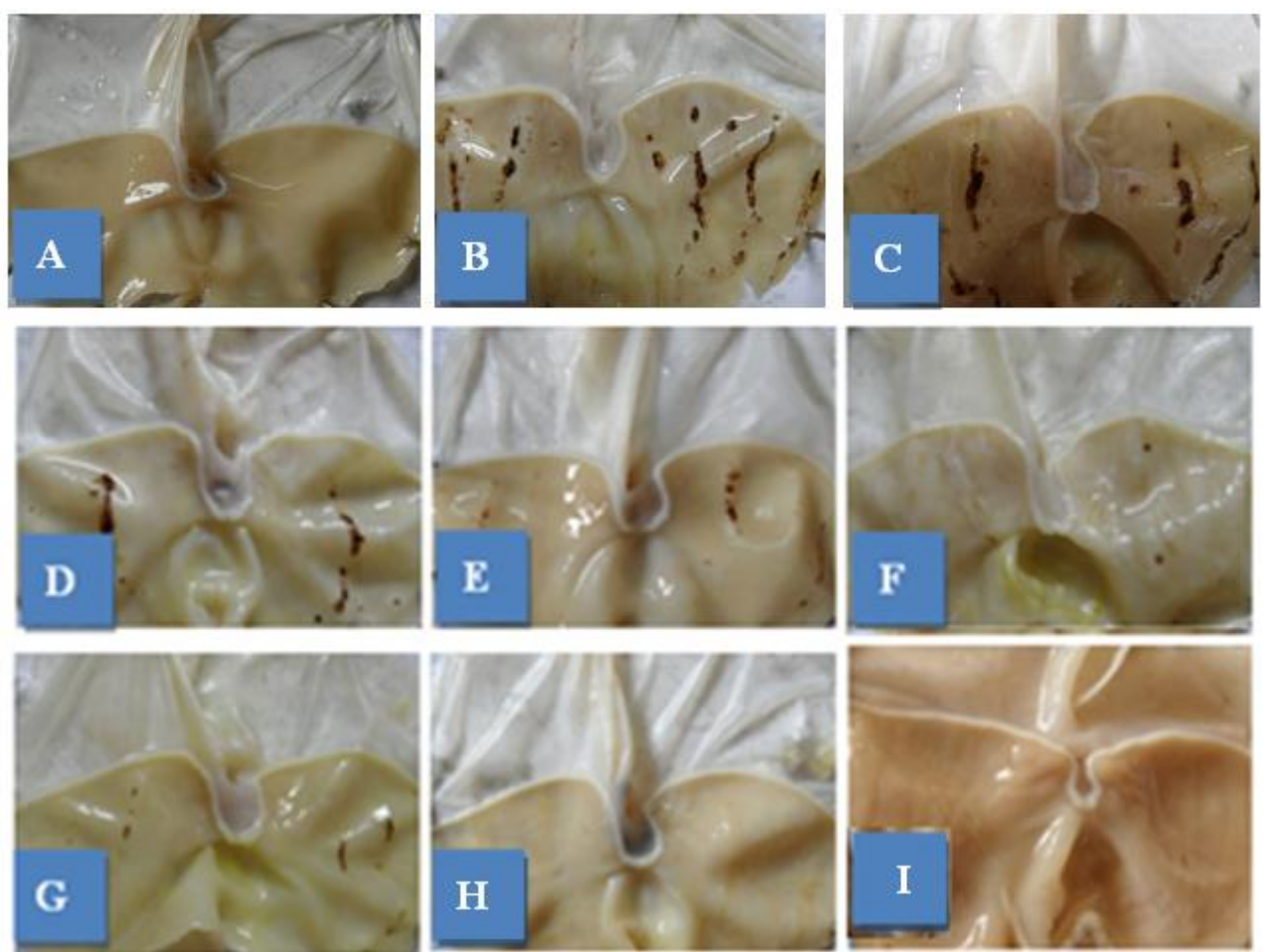

Fig. 1:- Photographs of the effect of Terminalia extract on gastric mucosal lesions induced by aspirin in rats of (A) control group, (B) aspirin group, (C), water extract I and aspirin, (D) water extract II and aspirin, (E) methanol extract and aspirin, (F) DCM extract and aspirin, (G) ethyl acetate extract and aspirin, (H) butanol extract and aspirin, and (I) ranitidine and aspirin. 

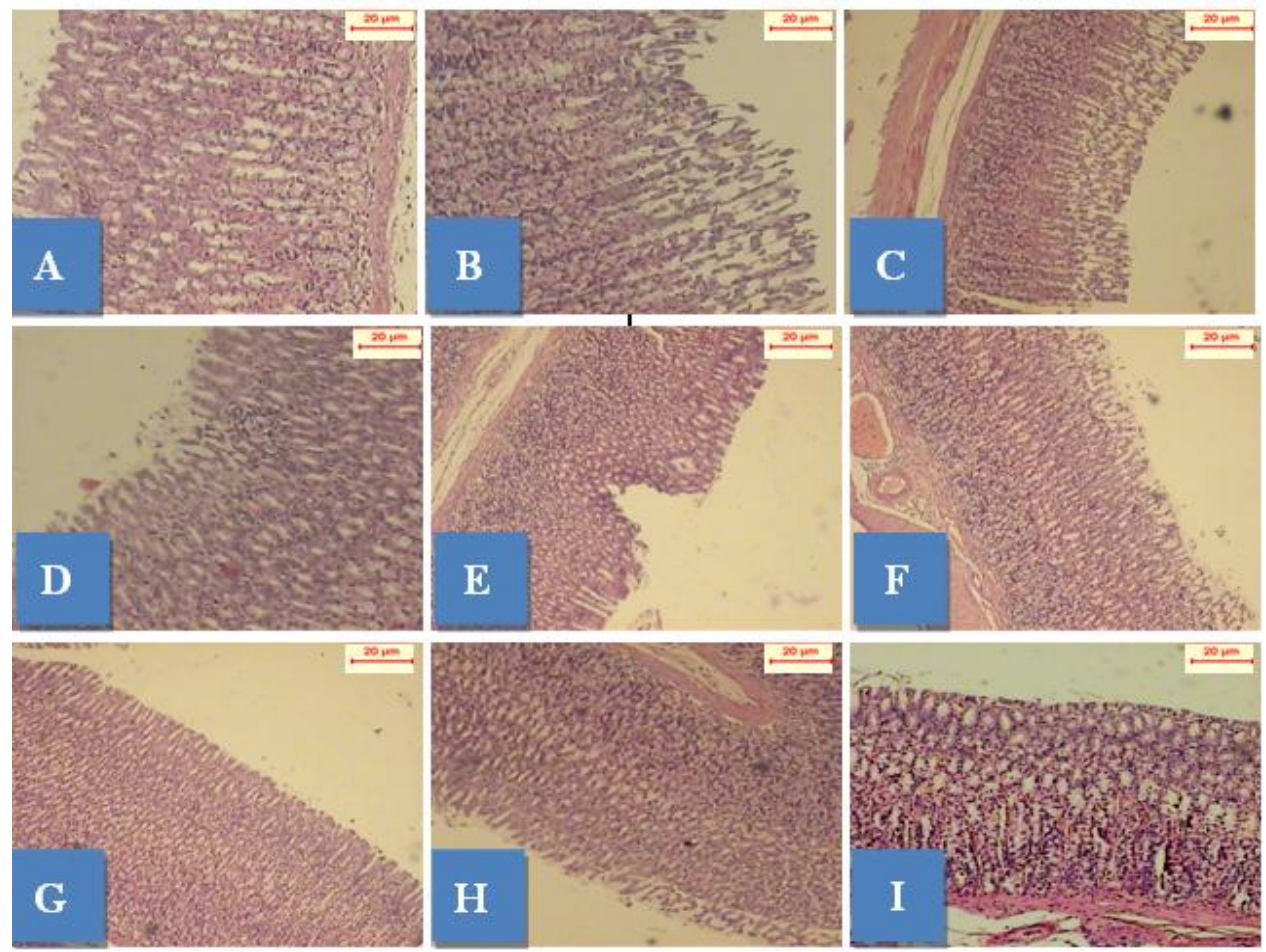

Fig. 2:- Protective effect of Terminalia on gastric mucosal lesions induced by aspirin in rats of (A) control group, (B) aspirin group, (C) water extract I and aspirin, (D) water extract II and aspirin, (E) Methanol extract and aspirin, (F) DCM extract and aspirin, (G) ethyl acetate extract and aspirin, (H) butanol extract and aspirin, and (I) ranitidine and aspirin (H \& E stain; scale bar: $20 \mu \mathrm{m}$ ).

Table 2:- Total phenol (mg of gallic acid equivalent/ g dry material) and total flavonoids ( $\mathrm{mg}$ of catechin equivalent/g dry material) of different extracts of Terminalia

\begin{tabular}{|l|c|c|}
\hline Extract & Total phenol & Total flavonoids \\
\hline Methanol & $56.57 \pm 4.71$ & $8.68 \pm 0.29$ \\
\hline DCM & $25.78 \pm 0.86$ & $4.84 \pm 0.02$ \\
\hline Ethyl acetate & $45.78 \pm 0.62$ & $9.71 \pm 0.18$ \\
\hline Butanol & $42.98 \pm 0.12$ & $5.84 \pm 0.25$ \\
\hline
\end{tabular}

Data presented as mean \pm SD

\section{Discussion:-}

The present studies have demonstrated that intragastric administration of different extracts of Terminalia laxiflora reduces aspirin-induced macrosopically visible mucosal damage in the rat stomach.

In the present work, stomach of aspirin group showed focal necrosis of gastric mucosa associated with mucosal and submucosal eosinophilic cells infiltration. Gastric mucosal erosion in the glandular part of the stomach, most often 1-4 $\mathrm{mm}$ in size, or petechial bleeding at the time of observations were present. These findings agree with the observation that aspirin administered intragastrically induces hemorrhagic as well as nonhemorrhagic damage to the mucosa associated with gastric bleeding and exfoliation of the gastric surface epithelium (Ashley, et al. 1985; Kitahora, and Guth 1987; Rowe, et al. 1987). Injury of the rnicrovascular supply of the stomach has been suggested to play a crucial role in the pathogenesis of mucosal damage caused by aspirin (Robins, 1980; Szabo, 1987). On the other hand, Olaleye, and Farombi (2006) stated that aspirin is a strong cyclooxygenase inhibitor that reduced gastroduodenal bicarbonate secretion, disrupts the mucosal barrier and endogenous prostaglandin biosynthesis, as well as mucosal blood flow. It elevates acid secretion and led to microvasculature damage by free radicals generation. Aspirin caused inhibition of prostaglandin synthesis. Prostaglandin is playing an important role for mucosal integrity and regeneration (Abdulla, et al 2010; Akuodor, et al 2012). 
In the results of histological investigation, the gastric mucosa of rats revealed that water, methanol, DCM and ethyl acetate and butanol extracts of Terminalia laxiflora absolutely inhibited the aspirin-induced alterations of rat stomach. Pretreatment with extracts of Terminalia laxiflora at dose of $(50 \mathrm{mg} / \mathrm{kg} \mathrm{bw})$ was found to preserve the functional cytoarchitecture of the entire gastric mucosa.

These findings confirm the cytoprotective nature of Terminalia laxiflora. Preliminary phytochemical screening of Terminalia laxiflora revealed the presence of flavonoids and total phenol. These phytoconstituents are well known to affect the integrity of mucus membranes and shown their ability to protect the cell against oxidative damage (Dela Pureta, et al. 2000; Suh, et al. 2003, Sumbul, et. al. 2011, Farzaei, et al., 2015). Flavonoids have excellent antioxidants effects that enhancing prostaglandin in the mucosal content. Besides this, they safeguard the capillary integrity and reinstate the normal function of the mucus membrane (Middleton. 1994; Carlo, et al. 1999; Kandaswami, and Rotelli, et al. 2003). Jawanjal et al. (2012) reported that the methanolic extra act of fruits of Terminalia belerica exhibit significant antiulcer property against aspirin induced ulcer. In addition, the study of Gupta et al., (2005) showed that the ethanol extract of Terminalia pallida Brandis exhibited significant anti-ulcer activity by enhancing antioxidant potential of the gastric mucosa, thereby reducing muocosal damage.

Our chromatic and analytical investigations showed that the butanol extract contains flavonids; red colour with Shinoda test Harborne and William (1975), among these active flavonoids, rutin was detected by using comparative paper chromatography, $\mathrm{Rf}^{*} 100$ values in 15\% Acetic is 48 and BAW (n-Butanol/acetic acid/water) as eluent is 42 in addition to several gallic acid derivatives, rosy red color with $\mathrm{KIO}_{3}$ reagent specific for gallotannins (Haddock et al., 1982) and ellagitannins through red color with $\mathrm{NaNO}_{2} / \mathrm{AcOH}$ test (Gupta et al., 1982). These phenolic constituents explain the gastroprotective activity of $T$. laxilora leaf extract.

From the results of this study, the butanol fraction showed the most potent gastroprotective extract. Previous studies of T. laxilora showed that it contains gastroprotective agents such as gallic acid, quercetin and rutin (De La Lastra 1994; Suzuki et al. 1998, Sen et al. 2013, Sumbul et al. 2011, Dubey et al. 2013).

Kandaswami, and Rotelli, et al. (2003) and Jawanjal et al. (2012) stated that rutin give an antiulcer activity by the inhibition of the proton pump. The authors concluded that rutin inhibits $\mathrm{H}^{+}-\mathrm{K}^{+}$ATPase, a key enzyme responsible for the secretion of acid, and thus shows antiulcer activity. On the other hand, Gallic acid possesses antiulcer activity (Govindarajan, et al. 2006, Sen, et al., 2013, Mard, et al., 2015). Quercetin reduced the gastric damage and this reduction confirmed a significant increase in mucus production (Martin, et al., 1993; de la Lastra, et al. 1994).

\section{Conclusion:-}

The different extracts of Terminalia laxiflora leaves gave varying degrees of anti-ulcer activity and could be a potential source of new anti-ulcer agents. The butanol fraction is the most potent gastroprotective extract. Thus, the protective effect of Terminalia laxiflora against gastric ulcer could be attributed to the presence of phytoconstituents in it.

\section{References:-}

1. Abdallah IZA, Khattaba AHK, Heebab GH. (2011). Gastroprotective effect of Cordiamyxa L. fruit extract against indomethacin-induced gastric ulceration in rats. Life Science Journal 8: 433-445.

2. Abdulla MA, Al-Bayaty FH, Younis LT, Abu Hassan MI. (2010), Antiulcer activity of Centella asiatica leaf extract against ethanol induced gastric mucosa injury in rats. J Med Plant Res 4 (13): 1253-1259.

3. Akuodor GC, Mbah CC, Essien AD, Akpan JL, Ezeokpo BC, Iwuanyanwu TC, et al. (2012): Ulcerprotective and antidiarrhoeal effects of the aqueous stem bark extract of Bridelia ferruginea in rodents. Pharmacolgia 3 (11): 591-597.

4. Alkofahi, A. and AH. Atta, (1999): Pharmacological screening of the antiulcerogenic effects of some Jordanian Mecicinal Plants in rats. J. Ethnopharmacol, 65: 341-345.

5. Ariypshi, I., Toshiharu, A., Sugimura, F., Abe, M., Matsuo, Y., and Honda, T. (1986) Recurrence during maintenance therapy with histamine $\mathrm{H} 2$ receptors antagonist in cases of gastric ulcers. Nikon University Journal of Medicine, 28: 69-74

6. Ashley S, Sonnenschein L, Cheung L. (1985) :Focal gastric mucosal blood flow at the site of aspirin-induced ulceration. Am J Surg 149:53-59. 
7. Carlo GD, Mascolo N, lzzo AA, Capasso F. (1999):Flavonoids: Old and new aspects of a class of natural therapeutic drugs. Life Sci. 65:337-353.

8. De Barros, M.P., Lemos, M., Maistro, E.L., Leite, M.F., Sousa, J.P.B., Bastos, J.K., de Andrade, S.F. (2008): Evaluation of antiulcer activity of the main phenolic acids found in Brazilian Green Propolis. Journal of Ethnopharmacology, 120(3), 372-377.

9. De La Lastra, C.A., Martin, M.J., Motilva, V. (1994): Antiulcer and gastroprotective effects of quercetin: a gross and histologic study. Pharmacology, 48(1), 56-62.

10. Dela Pureta R., Martinez-Dominguez E., Ruiz-Gutierrez V., (2000): Effect of minor components of virgin olive oil on topical anti-inflammatory assays, Zetschrift Fur Naturforschong 55 814-819.

11. Dubey, S., Ganeshpurkar, A., Shrivastava, A., Bansal, D., Dubey, N. (2013): Rutin exerts antiulcer effect by inhibiting the gastric proton pump. Indian journal of pharmacology, 45(4), 415.

12. Farzaei M.H., Abdollahi, M., Rahimi R. (2015): Role of dietary polyphenols in the management of peptic ulcer. World J Gastroenterol. 21(21): 6499-6517

13. Freitas CS, Baggio CH, Finau J, Anginoni M, Pizzolatti MG, Santos ARS, Marquez MCA. (2008): Inhibition of $\mathrm{H}+/ \mathrm{K}+$ ATPase in the gastroprotective effect of Baccharis illinita DC. J Pharm Pharmacol. 60:1105-10.

14. Govindarajan R, Vijayakumar M, Singh M, Rao ChV, Shirwaikar A, Rawat AK, et al. (2006): Antiulcer and antimicrobial activity of Anogeissus latifolia. J Ethnopharmacol. 106: 57-61.

15. Gupta, M., Mazumder, U.K., Manikandan L., Bhattacharya S., Senthilkumar G.P., Suresh R. (2005): Anti-ulcer activity of ethanol extract of Terminalia pallida Brandis. in Swiss albino rats. Journal of Ethnopharmacology; 97(2): 405-408

16. Gupta, R.K., Al-Shafi, S., Layden, K. and Haslam, E. (1982): The metabolism of gallic acid and hexahydroxydiphenic acid in plants. Part 2. Esters of $(S)$-hexahydroxydiphenic acid with Dglucopyranose $\left({ }^{4} \boldsymbol{C}_{\mathbf{1}}\right) "$, J. Chem. Soc. Perkin Trans I, 2525.

17. Haddock, A., Gupta, R.K., Al-Shafi, S. and Haslam, E. (1982): The metabolism of gallic acid and hexahydroxydiphenic acid in plants. Part 1. Introduction. Naturally occurring galloyl esters. J. Chem. Soc. Perkin Trans I, 2515.

18. Harborne, J. B. and William, C. A. (1975): "The Flavonoids" Chapman and Hall, London

19. Izzo, A.A., Carlo, G.D., Mascolo, N., Capasso, F. (1994): Antiulcer effect of flavonoids. Role of endogenous PAF. Phytotherapy Research, 8(3), 179-181.

20. Kandaswami C, Middleton E. (1994): Free radical scavenging and antioxidant activity of plant flavonoids. Adv Exp Med Biol. 366:351-376.

21. Kitahora T, Guth PH. (1987): Effect of aspirin plus hydrochloric acid on the gastric mucosal microcirculation. Gastroenterology 93:810-817.

22. Kumar A, Dewan B, Rama T. (2011): Evaluation of anti-ulcerogenic properties from the root of Flemingia strobilifera. J Basic Clin Pharm. 2(1).

23. Laine L, Takeuchi K, Tarnawski A. (2008): Gastric mucosal defense and cytoprotection: bench to bedside. Gastroenterology 135:41-60.

24. Mard S.A, Mojadami S., Farbood Y., Kazem M., Naseri G. (2015): The anti-inflammatory and antiapoptotic effects of gallic acid against mucosal inflammation- and erosions induced by gastric ischemiareperfusion in rats. Vet Res Forum. 6(4): 305-311.

25. Martin M. J., Motilva,V. Alarc, de la Lastra C. (1993): Quercetin and naringenin; effects on ulcer formation and gastric secretion in rats. Phytotherapy Research, 7(2): 150-153.

26. Jawanjal H, Rajput MS, Agrawal P, Dange V. (2012): Pharmacological evaluation of fruits of Terminalia belerica Roxb. for antiulcer activity. J Complement Integr Med. 9 (1): 1-12.

27. Mohiuddin, A.K.M.; Islam, Maidul; Mahmud, Shahin; Apu, Md. Aminul Islam, Halder, Joyanta, Khoka, Md. Sadek Hosen; Rakib, Hasibul Haque; Shome, Binita; Islam, Md. Shariful, A. (2015): comprehensive biological, ethnopharmacological and phytochemical update review on ayurvedic plant of Terminalia chebula (HORTOKI) of Bangladesh, World Journal of Pharmaceutical Research 4(5), 386-405.

28. Mota KSdL, Dias GEN, Pinto MEF, Luiz-Ferreira A, Souza-Brito ARM, Hiruma-Lima CA, BarbosaFilho JM, Batista LM. (2009):Flavonoids with Gastroprotective Activity. Molecules. 14:979-1012.

29. Muddathir A M, Yamauchi K, Mitsunaga T, (2013): Anti-acne activity of tannin-related compounds isolated from Terminalia laxiflora, J Wood Sci 59:426-431.

30. Muscara MN, Wallace JL. Nitric oxide. V. (1999): Therapeutic potential of nitric oxide donors and inhibitors. Am J Physiol 276:G1313-G1316. 
31. Nassar MI, Mohamed TK, Elshamy AI, El-Toumy SA, Abdel Lateef AM, Farrag AH. (2013):Chemical constituents and anti-ulcerogenic potential of the scales of Cynara scolymus (artichoke) heads. J Sci Food Agric, 93: 2494-2501.

32. Olaleye SB, Farombi EO. (2006): Attenuation of indomethacin and HCI/ethanol-induced oxitative gastric mucosa damage in rats by Kolaviron: A natural biflavonoid of Garcina kola seed. Phytothera Res $20: 14$.

33. Pillai, N.R., Suganthan, D., Seshari, C., and Santhakumari, G. (1978): Antigastric ulcer activity of nimbidin. Indian Journal of Medical Research, 68: 169-175.

34. Rashed K, Ono L.(2013): Phytochemical, Cytotoxic, anti- HSV-1 (Herpes Simplex Virus type- 1) and anti bacterial studies of Terminalia laxiflora Engl. and Diels, Hygeia. J. D. Med. vol.5 (2): 76-86.

35. Robins PG. (1980): Ultrastructural observations on the pathogenesis of aspirin induced gastric erosions. Br $\mathrm{J}$ Exp Path01 61: 497-504.

36. Rotelli AE, Guardia T, Juárez AO, de la Rocha NE, Pelzer LE. (2003): Comparative study of flavonoids in experimental models of inflammation. Pharmacol Res. 48:601-6.

37. Rowe PH, Starlinger MJ, Kasdon E, Hollands MJ, Silen W. (1987): Parenteral aspirin and sodium salicylate are equally injurious to the rat gastric mucosa. Gastroenterology 93:863-871.

38. Scheiman JM, Dubois, Giardiello FM. (1996): NSAIDs, Eicosonoids and the Gastroenteric Tract. Sounders: Philadelphia, 25: 102-108.

39. Sen, S., Asokkumar, K., Umamaheswari, M., Sivashanmugam, A., Subhadradevi, V. (2013): Antiulcerogenic effect of gallic acid in rats and its effect on oxidant and antioxidant parameters in stomach tissue. Indian journal of pharmaceutical sciences, 75(2), 149.

40. Sen, S. Asokkumar, K. Umamaheswari, A. M. Sivashanmugam, T. and Subhadradevi V. (2013): Antiulcerogenic Effect of Gallic Acid in Rats and its Effect on Oxidant and Antioxidant Parameters in Stomach Tissue. Indian J Pharm Sci. 75(2): 149-155.

41. Shirode D, Patel T, Pal Roy S, Jyothi TM, Rajendra SV, Prabhu K, Setty SR. (2008): Anti-ulcer properties of $70 \%$ ethanolic extract of leaves of Albizzia lebbeck. Phcog Mag. 4:228-31.

42. Suh, W.S.; Kim, Y.S. Schimmer, A.D.; Kitada, S. Minden, M.; Andreeff, M., Suh, N.; Sporn, M. Reed, J.C. (2003): Synthetic triterpenoids activate a pathway for apoptosis in AML cells involving downregulation of FLIP and sensitization to TRAIL, Leukemia 17: 2122-2129.

43. Sumbul, S., Ahmad, M. A., Asif, M., \& Akhtar, M. (2011): Role of phenolic compounds in peptic ulcer: An overview. Journal of Pharmacy and Bioallied Sciences, 3(3), 361.

44. Suzuki Y., Hayashi M., Ito M., and Yamagami I. (1976): Anti ulcer effects of 4' (2 carboxyethyl) phenyl trans 4 aminomethyl cyclohexanecarboxylate hydrochloride (cetraxate) on various experimental gastric ulcers in rats, Japanese Journal of Pharmacology, 26(4), 471-480.

45. Suzuki, Y., Ishihara, M., Segami, T., \& Ito, M. (1998): Anti-ulcer Effects of Antioxidants, Quercetin,. ALPHA.-Tocopherol, Nifedipine and Tetracycline in Rats. The Japanese Journal of Pharmacology, 78(4), 435441.

46. Szabo S. (1987): Mechanisms of mucosal injury in the stomach and duodenum: time-sequence analysis of morphologic, functional, biochemical and histochemical studies. Stand J Gastroenterol 22(127):21-28.

47. Tepperman BL, Jacobson ED. (1994): Circulatory factors in gastric mucosal defense and repair. In Physiology of the Gastrointestinal Tract, Johnson LR (ed.). Raven Press: New York.

48. Toma, W., Hiruma-Lima, C.A. Guerrerand, R.O. and Souza A.R. (2005): Preliminary studies of Mammea mericana L (Guttiferae) bark/latex extract point to an effective antiulcer effect on gastric ulcer models in mice, Phytomedicine, 12: 345-350.

49. Wallace JL, Miller MJ. (2000): Nitric oxide in mucosal defense: a little goes a long way. Gastroenterology 119: 512-520.

50. Wang M, Lee E, Song W, Ricciotti E, Rader DJ, Lawson JA, Puré E, FitzGerald GA. (2008): Microsomal prostaglandin E synthase-1 deletion suppresses oxidative stress and angiotensin II-induced abdominal aortic aneurysm formation. Circulation 117: 1302-1309.

51. Yuan Y, Padol IT, Hunt RH. (2006): Peptic ulcer today. Nat Clin Pract Gastr. 3:80-89.

52. Zilic S, Serpen A, Akılıog lu G, Gökmen V, Vancetovic J. (2012): Phenolic Compounds, Carotenoids, Anthocyanins, and Antioxidant Capacity of Colored Maize (Zea mays L.) Kernels. J Agric Food Chem, 60:1224-1231. 